\section{EMBRYRIDDLE}

Aeronautical University

SCHOLARLY COMMONS
Journal of Aviation/Aerospace

Education \& Research

Volume 9

Number 1 JAAER Fall 1999

Article 1

Fall 1999

\title{
A Model of "Applied Ethics" in Aviation Safety: The Aviation Safety Reporting System
}

LaMarr Stanford

Willem Homan

Follow this and additional works at: https://commons.erau.edu/jaaer

\section{Scholarly Commons Citation}

Stanford, L., \& Homan, W. (1999). A Model of "Applied Ethics" in Aviation Safety: The Aviation Safety Reporting System. Journal of Aviation/Aerospace Education \& Research, 9(1). https://doi.org/10.15394/ JAAER.1999.1235

This Article is brought to you for free and open access by the Journals at Scholarly Commons. It has been accepted for inclusion in Journal of Aviation/Aerospace Education \& Research by an authorized administrator of Scholarly Commons. For more information, please contact commons@erau.edu. 


\title{
A MODEL OF "APPLIED ETHICS" IN AVLATION SAFETY: THE AVATION SAFETY REPORTING SYSTEM
}

\author{
LaMarr Stanford and Willem Homan
}

Recently it was reported in the popular news media that 25 San Diego State University students were caught cheating on an ethics exam (Ristine, 1999). Internet sights like <www.schoolsucks.com> will sell you a canned essay for $\$ 19.97$ (Ware, 1999). The President, trying to escape responsibility for a tawdry affair, blatantly lies to the country on national television (Chen, 1998). As for aviation, imagine the following not-so-unrealistic scenarios involving airmen. The pilot of a Boeing 747 over the mid-Atlantic, with $400+$ passengers on board, descends through an assigned altitude and narrowly misses another airliner flying below. The $747 \mathrm{crew}$, fearful of ramifications, remains silent about the mishap. The other airplane's crew is unaware of their narrow brush with death, and since there is no radar coverage over the midAtlantic, the incident goes unreported. A young aspiring pilot surreptitiously adds some fictitious "Parker Pen" flight time in his logbook to obtain a job that requires more flight experience than he or she currently has.

The rational conclusion to all these events is that we are descending to the depths of a valueless nation. Situational ethics and self-serving rationalizations of any despicable situation seem to be not only accepted but expected. While this atmosphere is tolerated in many areas of society, there are niches where public safety considerations make it imperative that the substandard conduct of individuals in the system be exposed and corrected. The field of aviation safety is a prime example.

\section{SAFETY TRUTHS AND THE WALLS OF SILENCE}

A monumental scientific truth has emerged over the last 50 years of analyzing aviation safety statistics. Aviation safety experts have found that for every aviation accident there is a large number of related incidents that precede a final catastrophe. In other words, there are probably 500 near misses for every mid-air collision. It follows that if the aviation safety community can obtain a good sampling of these incidents for analysis, it can reliably predict where serious safety compromises may be developing and alert the industry. Incident reporting is a crucial link in the safety chain.

A current example of a serious safety concern emerging is the pilots' use of computers and automation on the flight deck. Airline pilots become very comfortable and dependent on these marvelous gadgets; however, these devices do experience failure and can be complex to program in a timecompressed situation. There is also a generation of senior pilots who are not as conversant and adept at using this computer-based technology interface as their junior co-pilots (Wiener \& Nagel, 1987). Furthermore, in recent years most of the new generation airliners have changed from a threeperson flight crew to just two pilots, consequently making automation more critical than ever.

In the early 1970 s, the aviation safety experts came to another monumental but frustrating conclusion. Many of the most informative and trend-setting incidents were not being reported, and the safety benefits were not being passed on to the aviation industry. The reason was simple. Incidents are often the result of errors and/or questionable judgement of the flight crew. What crew member with a mortgage and a family to support is going to voluntarily divulge self-incriminating information, even if it has serious safety consequences for other aviators? In this environment, flight crews simply remained silent and waited for the FAA or someone in the airline management to discover the incident. Airline management was often reluctant to report incidents as well. In fact, management faced the same dilemma as the pilots, namely the possibility of an FAA fine or some other sanction as a result of the incident. The upshot of the matter was that there was a wall of silence punctuated by the not too infrequent sound of aluminum bending and smashing.

The whole incident reporting system was founded on enforcement or policing action taken by the FAA through the use of informants and inspection procedures that often were ineffective. Moreover, the nature of incident investigation 
often put the FAA and the aviation community in adversary roles. The result was a "them-versus-us" mentality that impeded accurate incident reporting.

This situation set the stage for a deadly airline accident in 1974 (Shaw, 1974). The extent of the problem was painfully brought home after a TWA Boeing 727 crashed into the side of Round Hill, Virginia on December 1, 1974. All 92 passengers and crewmembers died instantly when the pilots prematurely descended past the minimum safe altitude on a night approach into Dulles Airport (NTSB, 1975). During the subsequent accident investigation, it was revealed that a United Airlines crew had mistakenly taken the same course of action on the same approach for the same runway just 6 weeks earlier. At the last minute, the United crew was able to see its mistake and take timely and safe corrective action. They reported the incident to United Flight Operations who, for obvious self-serving reasons, did not immediately pass it on to the FAA. The rest is history. The National Transportation and Safety Board, in its final report on the TWA 514 accident and the preceding United incident, stated:

In retrospect, the Board finds it most unfortunate that an incident of this nature was not, at the time of its occurrence, subject to uninhibited reporting and subsequent investigation, which might have resulted in broad and timely dissemination of the safety message issued by the carrier to its own flight crews. (National Transportation and Safety Board, 1975, p. 29)

\section{THE AVIATION SAFETY REPORTING PROGRAM}

Following the United incident and the subsequent TWA accident, the FAA realized that they could not have a policeman on every corner and an informant in every airline. A creative plan for drawing out the self-incriminating incident information was introduced to the aviation community. The idea was somewhat revolutionary for the time but may have been a derivative of the "whistle blowers" legislation directed at drawing out abuses in the environmental area and the military industrial complex. The key ingredient of the FAA's initiative was that any airmen (including air traffic controller, aviation certified mechanic, etc.) who voluntarily sent in incident information to the FAA within 10 days of an incident would be granted immunity from any penalties that may be imposed after an investigation of the incident took place. However, timing for the project was awkward. The Vietnam War had deeply divided the country. The only thing the public could agree on was that they all had a deep distrust of government. In this confrontational environment, the aviation community, led by the AOPA (Aircraft Owners and Pilots Association) and ALPA (Airline Pilots Association), soundly rejected this first initiative. The FAA had to deal with the issue of trust, or lack thereof. Under the proposed plan, every reported incident would be investigated and appropriate enforcement action taken. After the enforcement action was taken, the airman would get immunity from the penalty. The enforcement action would remain indefinitely on the airman's record in Oklahoma City. The risk was too high for the benefit gained to the airman. The wall of silence remained immovable.

Fortunately, the U.S. commercial aviation industry was genuinely safety-minded for many self-serving reasons. Airline pilots had a great deal of self-interest when it came to safety; after all, they were the first ones to the scene of any airline accident. Airlines also realized that dead passengers and destroyed airplanes made great headlines but were bad for business. Airplane manufacturers like Boeing and Douglas also knew that broken airplanes created a feeding frenzy for American Bar Association members.

As with any protracted negotiation, there is a point where someone finally comes up with a creative solution that meets most of the needs of all at the table. The missing keystone to the FAA's safety arch was respondent anonymity. Someone wisely suggested if the FAA were genuinely interested in only obtaining more safety information and not simply wanting to drop the hammer on more airmen, then this issue could be solved by an independent third party coming to the table. The "honest broker" turned out to be the National Aeronautics and Space Administration (NASA).

The final agreement between the parties came together in this way (FAA, 1997):

- The FAA contracted with NASA basically to operate the FAA's Aviation Safety Reporting Program (ASRP). NASA called its part of the partnership the"Aviation Safety Reporting System" (ASRS). In the end, NASA subcontracted the actual operation of the program out to Battelle Memorial Institute in Columbus, Ohio. However, most aviators kept calling the incident reporting document "the NASA form."

- The crucial position of respondent anonymity 
was assured by NASA's involvement. A pilot reporting an incident would have any identifying information laundered from the report before it was passed along to the FAA. Consequently, in nearly all cases, the FAA did not have enough identification information to go and investigate the reported incidents. They had the safety information, but not the specific pilot or airline identification, which was essential for enforcement action. The FAA still had to rely on its traditional means of enforcement through informants and spot inspections. The aviation community was so paranoid about this issue that the FAA promulgated Federal Aviation Regulation (FAR) 91.25, which specifically prohibited the FAA from using any information on the ASRS form for enforcement purposes (FAA, 1995). To further illustrate the importance and effectiveness of the "respondent anonymity" concept, one needed only to look at a recently published FAA notice to proposed rule-making: "Protection of Voluntarily Submitted Information" (FAA, 1999). This proposed Federal Aviation Regulation referred to data-sharing programs (called ASAPs), in which persons in the aviation community, such as air carrier operators, would voluntarily share with the FAA information related to safety. An impediment to further development of these programs was the reluctance of people to share information that, when in the hands of a government agency, may be required to be released to the public through the Freedom of Information Act or other means. Clearly, if the privacy of the shared information were guaranteed the effectiveness of these data-sharing programs would increase.

- Pilots who used the ASRS were granted immunity or a waiver from any penalties that arose from any subsequent FAA enforcement action. If convicted, the violation would be reported on the pilot's record, but he or she would not have to serve the proposed suspension or pay the fine. However, the FAA flatty stated that there would be no immunity if the incident was caused by a deliberate act of the airman, was criminal in nature, or resulted in an accident.
- Airmen had 10 days from the date of the incident to file a report. The FAA did not want to give a negligent pilot the benefit of immunity from a penalty if the airman filed a report only after the incident happened to be investigated some weeks or months later. Subsequent enforcement actions by the FAA have indicated that they have been very strict in the interpretation of the 10-day filing period.

- A key condition of this social contract was that an airman could not take advantage of the immunity or waiver of penalty more than once every 5 years. This did not prohibit the filing of numerous incident reports, but an airman could exercise the immunity provision only once, and then he or she would lose the immunity for the 5 subsequent years. This obviously was introduced to reduce the recidivism rates.

\section{FILING AN ASRS REPORT}

As a social contract, the ASRS has worked remarkably well. Since its inception in 1975 , over 420,000 incident reports have been filed, and current monthly reports range from 3,000 to 4,000 . NASA employs about 15 former airline pilots, air traffic controllers, flight attendants, and mechanics to do the initial and subsequent in-depth analyses of the incoming incident reports (Yodice, 1999). The ASRS acts on the information contained in these reports. It identifies system problems and disseminates the information through its CALLBACK newsletter, its Directline journal, and research studies. In fact, the ASRS database is a public repository, which serves the needs of all agencies and organizations involved in the promotion of aviation safety. The following is an overview of how NASA processes an incoming incident report:

- After an incident report is received at NASA's Ames Research Center at Moffet Field, Califormia, it is date stamped. Normally, the postmark is the relevant date stamp used for the 10-day filing period; however, if it is missing, the NASA stamp becomes crucial.

- The report is passed on to an analyst for initial screening. The analyst can contact the reporting airman, since the home telephone number is included in the top portion of the report. Sometimes clarification is needed to fully analyze the nature of the incident. 
- Reports involving accidents and/or criminal activity are passed on to the NTSB and/or the U.S. Attorney's offices with the airman's identification intact.

- If a clear and immediate safety issue is raised, the data are immediately passed on to the FAA and the NTSB by way of an "Alert Bulletin." NASA removes the identification of all the parties in the Alert Bulletin. A good example of this concerns Boeing 737 airliners. If NASA receives any reports about rudder malfunctions on this particular aircraft, it immediately issues an Alert Bulletin. This aircraft has been involved in several fatal accidents involving suspected uncommanded rudder excursions. Recently, the NTSB announced the probable cause of two of these accidents to be an uncontrolled rudder reversal. However, the different agencies, as well as the manufacturer, are still stumped as to the actual cause of these accidents; therefore, they want to get all the possible incident information involving the B-737 to assist them in preventing future occurrences (McKenna, 1999).

- Reports of a less time-sensitive nature are analyzed and grouped or coded into various categories in the database.

- At this point, the analyst launders the report of any identification clues. The top portion of the form is used by the airman for his or her return address and telephone contact number. This top portion is removed along with the date stamp and returned by regular mail to the airman. This becomes the airman's proof of reporting the incident if subsequent enforcement action is taken.

- After all the relevant safety data have been extracted from the report, it is destroyed. The only evidence that the report ever existed remains in the hands of the reporter to be possibly used at some future date.

Finally, contrary to what many airmen may suspect, the filing of a report with NASA concerning an incident or occurrence involving a violation of the FARs is considered by the FAA to be indicative of a constructive attitude.

\section{AN AVIATION SAFETY SUCCESS STORY}

As the program enters its 25th year, we should ask ourselves: Why has the ASRS worked so well? The FAA has to take some major credit for the success. The government leadership in the early 1970 s was genuinely interested in aviation safety. They chose to initiate a carefully structured balancing act between safety concerns and regulatory/enforcement policy. They came to some of the following conclusions, which prompted the novel approach:

- The public was not about to confess altruistically to each and every negligent safety violation. If something was going to elicit the required safety information, it needed to have a very strong selfinterest component to it.

- With a limited number of enforcement officers (about 4,000 aviation safety inspectors nationwide), the FAA could not put a cop on every corner. In contrast, the New York Police Department has over 44,000 policemen (NYPD, 1998). The city could literally place a cop on every street corner.

- While enforcement was not the goal of the ASRS, it was clearly evident that strong enforcement was the necessary motive force needed to flush out the incident reports. If pilots knew that the incident would never be detected by the FAA, they would be less inclined to report it. The fear of detection was and is the main underlying force for the entire program. When effective enforcement is augmented by a self-serving immunity provision, the incident information floods in. When the incident information flows, accidents, with the resultant pain and suffering, are avoided.

What does the ASRS tell us about professional ethics in the aviation industry? Airmen are a very well educated, highly trained, and well paid group in a very high technology area of our society. Notwithstanding all these positive qualities, this group of professionals will not altruistically and voluntarily step forward and report safety violations that may impugn their professional competence and threaten their livelihood.

The FAA's Manager of the Aviation Safety Reporting Program in Washington D.C. recently reported that the Stanford University Health Sciences Center showed a great deal of interest in implementing something similar to the ASRS in the healthcare field (M. Blazy, personal communication, June 16, 1999). Medical authorities are starting to realize that thousands of safety incidents go unreported among healthcare practitioners. They also realize that there is an impenetrable wall of silence. While most pilots' mistakes are written up in the next day's newspaper, 
doctors get to quietly bury theirs.

Clearly in the health care industry the threat of enforcement and the sanctions associated with violations and incidents are somewhat different from what we are used to in aviation. In fact, many medical centers and insurance companies have been trying to monitor the incidence of adverse outcomes in surgery cases and are looking for opportunities for early intervention in other medical interventions. These organizations feel that both the patient outcome and the claim outcome can be favorably influenced by early, appropriate intervention. They therefore encourage surgeons to call in incident reports. They also remind them that while there is no penalty for making an incident report, there may be a penalty for failing to do so. Another incentive for participation in incident reporting programs by health care providers could be lower malpractice insurance rates. Furthermore, just as with the ASRS, respondent anonymity is a key ingredient to a successful program. Finally, several specialized medical incident reporting systems have been in operation in other countries. A case in point is the Critical Incident Reporting System at the University of Basel, Switzerland. This program focuses on incident reporting in the field of anesthesiology (Helmreich, Schaefer, 1994). One has to realize though that regardless of the field, there has to be a self-serving immunity provision to make the program work.

\section{CONCLUSION}

The question of ethical behavior among our educated elite cannot be answered in a positive way. No one wants to take responsibility for his or her negative actions today. To use an old hockey expression, "everyone wants to skate" or dodge the consequences of their advertent or inadvertent actions. The law refuses to recognize or enforce ethical or moral standards among our professional or political elite, so each responsible group in society must attempt to overcome this natural tendency to "skate," especially when public safety issues are involved. Nowhere is this more important than in the fields of healthcare and commercial aviation.

The ASRS, through compromise and an appeal to selfinterest, does a remarkably good job of eliciting this crucial information in a largely unethical society. The results speak for themselves. Americans enjoy the safest public air transportation system in the world. Last year was the safest year in airline history in this country; no major U.S. airline suffered a fatal accident in 1998. The ASRS program undoubtedly contributed in some degree to this outstanding safety record.

Future challenges in the area of incident reporting will include the design of more sophisticated tools to review and analyze the data generated by the incident reporting systems. Researchers also need to develop more specific methodologies to capture and analyze human factors information. Unless contimued progress is made in these areas the usefulness of incident data gathering will become questionable. However, none of these technical recommendations have any meaning without the overall integrity of the reporting system. In fact, failure to safeguard the anonymity and the procedures associated with the ASRS or any other incident reporting system can result in long-term tragedy (=accidents) and a violation of public trust. $\square$

LaMarr O. Stanford graduated from the University of Alberta Law School in 1976. In 1989 he graduated from the Institute of Air and Space Law at MCGill University with a graduate aviation law degree (LLM). Before joining academe he was a practicing aviation attorney with a government agency and thereafter in the private sector. He has over 4,500 hours of flight time and holds an ATP license and Flight Instructor rating. He teaches Aviation Law, Aviation Economics, and Electronic Navigation in the Aviation Department at the State University of New York at Farmingdale, where he is an Associate Professor.

Willem J. Homan received a Doctorate in Leadership from Northern Arizona University and an MBA from Arizona State University. He also completed a Master's in Aeronautical Technology at Southeastern Oklahoma State University and is a licensed pilot (ATP) and flight instructor. He teaches Aviation Law, Aviation Safety, and CRM in the College of Aviation at Western Michigan University, where he is an Associate Professor. 


\section{REFERENCES}

Chen, E. D. (1998, September 14). Both sides urge Clinton to admit he told lies. Los Angeles Times, p. Al.

Federal Aviation Administration. (1995). Prohibition against use of reports for enforcement purposes (FAR 91.25). Washington, DC: U.S. Government Printing Office.

Federal Aviation Administration. (1997). Aviation Safety Reporting Program (AC 00-46D). Washington, DC: U.S. Government Printing Office.

Federal Aviation Administration. (1999, July 26). Protection of voluntarily submitted information; proposed rule. Federal Register 64(142), 40472-40482.

Hamilton, J. S. (1996). Practical aviation law. Ames: Iowa State University Press.

Helmreich RL, Schaefer HG. (1994) Team performance in the operating room, pp 225-253. In Bogner MS (Editor) Human Error in Medicine, Hillsdale, New Jersey.

McKenna, J. T. (1999, March 29). Commercial transports face new scrutiny in U.S. Aviation Week \& Space Technology, $150(13), 38-39$.

National Aeronautics and Space Administration. (1984). Aviation Safety Reporting Form (ARC Form 227). Washington, DC:

U.S. Government Printing Office.

National Transportation and Safety Board. (1975). TWA. Boeing 727-231, N54328, Washington-Dulles IAP, December 1. 1974. (NTSB-AAR-75-16). Springfield: National Technical Information Service.

NYPD (1999). Who we are. New York Police Department home page. Available: www.ci.nyc.us/nypd/home.html.

Ristine, J. (1999, April 30). Cheating sting nets 25 at SDSU. The San Diego Union-Tribune, pp. B-1:1, 7, 8; B-3:3.

Shaw, A. (1977). Sound of impact: The legacy of TWA Flight 514. New York: Viking Press.

Stanford, L., \& Homan W. (1999, June). Ethics and safety in aviation-The Aviation Safety Reporting System. Presented at the Integrating Ethics into Technical Education Conference, Somerville, NJ.

Ware, J. C. (1999, May). Cheat wave. Yahoo! Internet Life, 5, 102-104.

Wiener, E. L., \& Nagel, D. C. (1987). Human factors in aviation. San Diego: Academic Press.

Yodice, J. S. (1999).The Aviation Safety Reporting Program. AOPA Pilot, 5, 124-125. 